through the sphygmophone. In the sphygmophone, as I originally constructed it, the needle marks out the pulse curves over a plate of carbon or of metal inserted in the circuit of Professor Hughes's microphone. I mount on a slip of talc, glass, wood, or ebonite a plate of metal or of gas carbon, and place it as if about to take a tracing of the pulse by the sphygmograph. Then I connect one terminal from a battery of one or two cells to the metal or carbon plate and the second terminal from the battery to one terminal of a telephone. Lastly, I connect the other terminal of the telephone with the metal rod of the support which carries the needle that is moved by the pulse. When the needle, under the pulse movements, makes its tracing on the carbon or metal plate, it completes the connexion between the telephone and the battery, and in the act causes a distinct series of sounds to be produced by the telephone, which sounds are in accord with the movements of the pulse. The sounds heard are three in number : one long and two short, corresponding to the systolic push, the arterial recoil, and the valvular check or chuck.

Of late, in using the sphygmophone, I have discarded the microphone, having found a mode of working with sufficient clearness, for clinical purposes, by letting the needle simply traverse a resonant surface of parchment stretched across a ring of light metal; but this yielded too feeble a sound for the present experiment. The battery was therefore again resorted to, with the microphone, as in the first adaptation, and the battery power was so increased that the sounds emitted through the telephone from the pulse movements were as loud as the human voice in ordinary conversation. The pulse was in this way made to record its action through the mouth of the telephone to the mouthpiece of the graphophone, so as to write its record on the revolving wax cylinder, and the record written, the graphophone was made to give it back in sounds, which came out in the most distinct manner. The three pulse sounds were as clear, when there was perfect stillness, as they were from the sphygmophone direct, and the record remained in such permanency that many hundred repetitions of it could be secured and repeated in any part of the world at the will of the possessor of the cylinder on which it was traced, if the graphophone were at command to develop it. On Saturday night last at least a luundred persons heard the tracing of one pulse quite distinetly.

In the manner described I have now taken impressions on the wax cylinder of several varieties of pulse : intermitttent, irregular, full, quick, slow; and the respective qualities of each are easily heard. To the process only one serious objection can be taken-namely, that with the pulse beat there is an accompanying buzz or nurmur which is produced by the instrument, and which somewhat troubles the listener. This complication will, it is expected, be overcome in the course of improvements in construction.

Cough Reading by the Graphcphone.-From recording the oulse on the wax cylinder of the graphophone, I moved to the recording of coughs and coughing sounds upon it. In this case the results were exceedingly definite and practical. The cough has simply to be taken as the speaking and singing voice is taken and the return cough by the graphophone is as clearly distinct as the original. On one cylinder I took four varieties of coughs-namely, a loose bronchial, an asthmatic spasmodic, a dry bronchial, and a barking and hacking cough. In listening to these coughs it is difficult to divest the mind of the belief that it is not the patient, actually, who is producing the effect by his own present efforts.

Cui bono?-To what service the facts related above may in course of time be applied it is difficult to say, for this is the first word on the subject, the mere mite in science, which, like the mite in charity, has to be taken rather for the worth of the intention than for any immediate or real practical application. Out of a roll of paper, accidentally ased by Laennec, the stethoscope was elaborated, and a new mode of diagnosis, widest perhaps of any, was brought into existence, a truth which proclaims that out of the simplest of simple things the greatest may arise. It may be so here.

In regard to the pulse, it may fairly be said that when a sphygmographic tracing, readable by the eye, can be fixed on paper and sent by post anywhere, it is needless to fix a similar record on a wax cylinder in order that it may be placed in another instrument to be received by the ear. \$till, as I have shown eleswhere, there are some special advantages in the sphygmophone which have yet to be appreciated, and which the plan I have described makes permanent. Therefore I would not throw away what little has been gained respecting the pulse because it is little.

On the matter of the cough record much may at once be said in its favour. To be able to compare a cough of to-day with a cough of a month or a year ago would be a good clinical observation, and may be so immediately available in the consulting-room that $I$ have determined to bring it into practice in mine. For lecture purposes also this part of the work would be most useful, since every class of cough could be taught to the student by direct practice and demonstration.

Finally, the different kinds of cries indicative of different sensibilities to pain can be rendered diagnostically. In a word, any sound whatever indicative of health or disease, and any animal motion of health or disease that admits of being translated into sound, can now be recorded, made permanent, and reproduced any number of times, either for comparison, demonstration, or observation. The utilisation of such a power in medicine, once gained, cannot, I think, be lost, and I am happy in having the opportunity of first unfolding it in the columns of THE LANCET.

IIanchester-square, W.

\section{TOTAL STAPHYLOMA OF THE CORNEA CORRECTED BY AN OPERATION.}

BY J. R. WOLFE, M.D., F.R.C.S.E.,

SURGEOX TO TIIE GLASGOW OPHTHALNIC INSTITUTION, AND LECTURER ON OPHTHALMOLOGY IN ANDERSON'S COLLEGE.

When asked by the President of the Glasgow MedicoChirurgical Society, some time ago, to make some remarks on a paper which had been read on an operation for staphyloma of the periphery of the cornea and limbus, I said that the only remark I could offer was that I hoped the author would not repeat the operation. I explained at the time that I regarded it as an established principle that the ciliary region is a dangerous one for the surgeon to operate on. So strongly do I hold this opinion that I am in the habit of laying it down as a rule that, in cases of cuts or tears of the cornea and sclerotic causing an escape of the vitreous, the conjunctiva covering the sclerotic should be brought together by sutures, but the limbus left alone, thus giving nature an opportunity of healing the wound gently by contraction and cicatrisation. A ligature in that region might strangulate the ciliary nerves, and thus prove fatal both to the injured eye and also by sympathy to its fellow, as in cases of traumatic tetanus. I was reminded of this incident the other day, when I read in the Annales d'Oculistique a paper written by one of the leading ophthalmologists in Belgium. ${ }^{2}$ The case described was that of a boy aged five years, who lost the sight of his right eye by an attack of conjunctivitis, which was thought to be of a diphtheritic character. The eye became distended by a staphyloma of the cornea; the left eye was perfectly healthy. The staphyloma was excised with all the usual antiseptic precautions, not omitting the sterilisation of the instruments; and yet on the third day photophobia commenced in the other eye, which ultimately became blind, notwithstanding the subsequent but, as it proved, too long delaved enucleation of the staphylomatous stump. The author concludes the history of the case with the following words in capital letters: "Such are the facts with their brutal eloquence."

With regard to the pathology of sympathetic ophthalmia, I shall only remark, in passing, that I consider the ciliary nerves to be the primary, if not the only cause. As to the theory of infection by the migration of microbes along the sheath of the optic nerve of one eye to that of the other, I appeal to Professor Sattler, who, in my opinion, is the highest authority on that subject. He thinks that the microbes found in an eye suffering from sympathia are not the staphylococcus pyogenes aureus of Deutschmann, but a special microbe, the nature of which he has not yet determined. Perhaps it may turn ont to be the pigment of the choroid altered by disease. Regarding these microbes, therefore, as so many entities and quiddities, I shall par Dr. Van den Burgl. Bruxelles, Oct 1888 
adhere to my own doctrine, which is based upon clinical experience. It gives sufficient reason for my objection to surgical interference with a partial staphyloma which involves the border of the cornea and sclerotic. If the eye be troublesome, or if it disfigure the face, enucleation is the only safe remedy. The case, however, is quite different when the staphyloma is situated at the anterior pole of the eye and the distension has taken place at the expense of the cornea alone. In such a case, $I$ correct the deformity and relieve the pain without sacrificing the eyeball.

John $\mathrm{H}-$, niner, aged thirty-five, while working in the pit thirteen months ago, received a blow with a stone on the right eye. Three days after the injury the sight was gone, and the pain, which was slight at first, became excessive. Poultices, fomentations, and other remedies were applied, but without relief. For seven months, during which he was off work, he spent sleepless nights. He was admitted into the Ophthalmic Institution on Oct. 14th. The eyeball was distended at the expense of the cornea, which was opaque, soft-looking, and denuded of

FrG. 1.

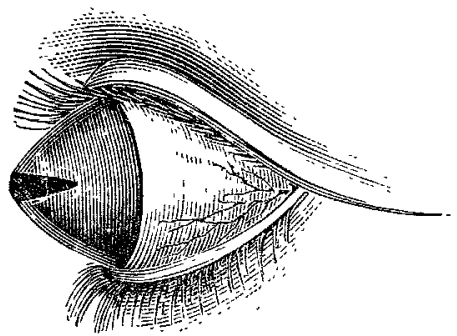

Showing the size of the staphyloma; the black shows half of the corneal flap removed.

its anterior elastic layers. The distension was as big as a large bean and pear-shaped, the point looking forwards. The ciliary region was also distended and out of shape, and the globe was visible when the eyelids were closed. The whole eyeball was highly injected, and tender to the touch. After several applications to alleviate the pain, I operated on the eye on Nov. 1st. The patient was put under chloroform by Dr. Macgregor Robertson, who also separated the eyelids, instead of using a speculum. An oval-shaped flap was removed from the centre of the cornea. (Fig. 1.) The lens, which was hard and of a yellow colour, now presented itself, and was removed, its removal being followed

FIG. 2.

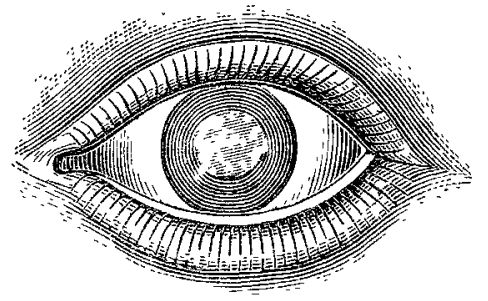

Showing the appearance of the eye four months after the operation.

by a small escape of vitreous. The edges of the wound were brought together by a fine needle and silk thread, and adhesive court-plaster and bandage applied to the eyelid. On the third day the eye was opened and the ligatures removed. The edges of the wound were closely applied, and the eyeball had its natural size and shape. On the eighth day the patient was dismissed cured. Up to the present date, after the lapse of nearly four months, when the patient was shown to the Society, there has been no return of pain, and the eveball looks as well as we could desire (Fig 2). With a little tinting, it might have almost the same appearance as the other eye.

Glasgow.

Darenth Asylum.-On March 13th Mrs. Dyer, the much beloved and respected matron of Darenth Asylum, was presented with a very handsome travelling trunk and literary machine by her nurses, and a beautiful little workbasket by the patients. Mrs. Dyer has been an officer of the Metropolitan Asylums Board for thirteen years, and her retirement (owing to ill health) is universally regretted.

\section{AN ACCOUNT OF \\ THREE CASES OF FRIEDREICH'S DISEASE, OR HEREDITARY ATAXIA.}

By J. MICHELL CLARKE, M.A., M.B., M.R.C.P., ASSISTANT PHYSICIAN, BRISTOL, GENERAL HOSPITAL; ASSISTANT LECTURER ON PHYSIOLOGY, BRISTOL MEDICAL SCHOOL.

THE father of these patients, a butcher, sufiered from heart disease and dropsy, and died in an asylum, apparently of melancholia. His parents died of old age, his father living to be ninety-six ; one of his sisters committed suicide ; family healthy. The mother is still living. Her father's father died at the age of rinety-nine, and her mother at the age of a hundred and one. Her father lost all his hair before he was thirty years old, and died of diabetes; her mother died at the climacteric period. There were two other suns and another daughter, all of whom survive. They had fourteen children-(1) Georgina, aged thirty-seven, healthy; (2) Albert, aged thirty-five (one of the patients); (3) George (drowned); (4) lsaac (died of croup); (5) a son, aged twenty-five (examined and found healthy); (6) William, and (7) Mary Ann (both died, at the age of five months, of "weakness"); (8) Lizzie, aged twenty-one (examined and found healthy); (9) a daughter (died at the age of one month, overlaid) ; (10) Caroline, aged eighteen (one of the patients); (11) Isaac (died, at the age of three years, of croup); (12) Joln, aged fourteen (examined and found healthy); (13) Isaac, aged eleven (one of the patients); (14) a child prematurely born at seven months (died in three days). The father was a heavy drinker; no evidence of syphilis could be obtained. The mother is a strong, healthy woman, and does hard work. Has never suffered from fits, from any nervous affection, or any severe illness. She was carefully examined as to state of reflexes $\& c$, and found to be normal in every respect.

CASE 1.-The first patient, Albert A-, aged thirtyfive, is a pale, pasty-faced man, fairly well nourished. He has lost the greater part of his hair. He never had any severe illness; has had gonorrhœa, but not syphilis. He never had fits, or any loss of consciousness. He is said, when aged five years, to have looked "silly"- that is, he could not stand still, rocked to and fro when standing, and kept his mouth open; he had frequent falls, and appeared to throw himself about when walking. He worked as an errand-boy till the agre of twenty, when he had to leave off on account of falling frequently and dropping the things he carried. Since then he has been unable to work in consequence of growing clumsiness and weakness, the latter gradually increasing so much that he has become unable to stand without support. Physical examination showed the thoracic and abdominal organs to be normal. When he is sitting down slight irregular movements of the body and head are seen, the latter being moved up and

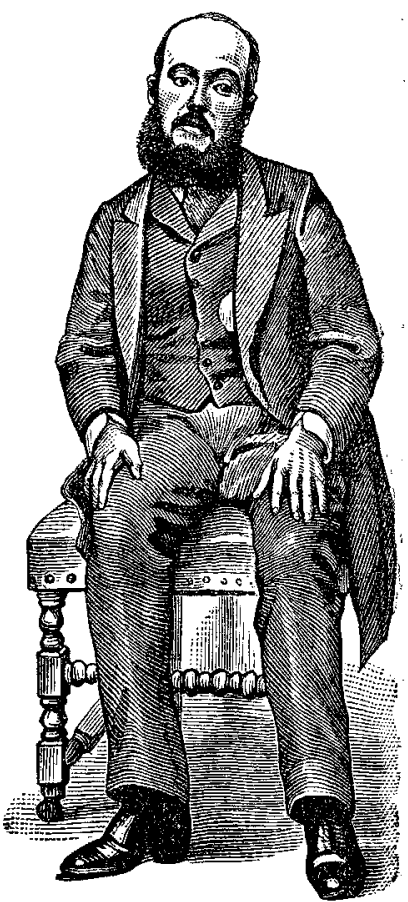

down or swayed from side to side. He is unable to stand. unsupported, and when he rises from a sitting posture the feet are brought forcibly and ataxically to the ground wide apart from one another. When standing with the aid of some support, the swaying, irregular movements of the head, trunk, and limbs, and the irregular movements of the tendons on the dorsum of the foot, are very marked. The gait is very ataxic, resembling that of a drunken man; the feet are not raised high; he stagrers from side to side and often crosses his legs. Movement of the arms is also ataxice.g., he touches the mouth with the forefinger instead of the nose; and when told, the arms being extended, to bring his forefingers together, fails to do so exactly, or 